\title{
A ARGUMENTAÇÃO EM MATEMÁtICA NA INTERAÇÃO COM TECNOLOGIAS
}

\author{
Nilce Fátima Scheffer
}

Departamento de Ciências Exatas e da Terra/URI; Erechim, RS e-mail: snilce@uricer.edu.br

\section{Resumo}

Este trabalho tem por objetivo apresentar dados de pesquisa realizada com estudantes e professores de Ensino Fundamental e Médio, a respeito da "Valorização da argumentação nas aulas de matemática, a partir da interpretação de gráficos de funções na Calculadora Gráfica TI-83 e no software Winplot". Neste artigo, apresentam-se reflexões teóricas a respeito da Linguagem e suas formas de Representação, da Produção de Argumentação em torno de situações interpretativas de matemática, além das Tecnologias Informáticas e Educação Matemática. O estudo se concretizou em três momentos, na Iniciação Científica, em que se evidenciou a ocorrência de expressões argumentativas na linguagem de estudantes; na Extensão, quando se desenvolveram oficinas de informática com estudantes e professores de Ensino Médio, momento em que se coletaram os dados a partir de filmagem das sessões; e, no terceiro momento, com o Trabalho de Conclusão de Curso, o estudo se completou, concentrando-se basicamente na análise da argumentação presente nas narrativas e nas linguagens verbal, não-verbal e escrita de professores de matemática de Ensino Médio. O presente texto foi produzido e apresentado em palestra desenvolvida na II Escola de Inverno de Educação Matemática que ocorreu na Universidade Federal de Santa Maria - UFSM RS, no ano de 2010. Palavras-chave: argumentação, matemática, tecnologias informáticas, representação. 


\section{Abstract}

This paper aims to present the result from a research conducted with students and teachers from Elementary and High School about the "Valuation of argumentation in mathematics classes, from the interpretation of function graphs on the TI-83 Graphing Calculator and on the software Winplot ". This paper presents theoretical reflections about the Language and its forms of Representation, the production of argumentation regarding interpretative situations of mathematics besides Computing Technologies and Mathematics Education. The study took place in three moments, on Scientific Initiation where one has revealed the occurrence of argumentative expressions in the language of the students, on the Extension when was developed computing workshops with students and teachers of High School, moment when information were collected from records of the sessions, and in the third moment that was with the Course Conclusion Work. With that the study was completed, focusing basically on the analysis of argumentation present in narratives and verbal, nonverbal and written languages of math teachers of High School. This text was produced and presented in a lecture developed at the Second Winter School of Mathematics Education which took place at the Federal University of Santa Maria - RS UFSM in 2010.

Keywords: argumentation, mathematics, computer technologies, representation.

\section{Introdução}

Este trabalho tem por objetivo apresentar dados de pesquisa realizada com estudantes e professores de Ensino Fundamental e Médio, a respeito da "Valorização da argumentação nas aulas de matemática, a partir da interpretação de gráficos de funções na Calculadora Gráfica TI-83 e no software Winplot”.

Cabe ressaltar que este trabalho vem sendo desenvolvido em diferentes frentes que abrangem: Iniciação Científica, Extensão e Trabalho de Conclusão de Curso, orientados pela autora. Na Iniciação Científica, evidenciou-se a ocorrência de expressões argumentativas na linguagem de estudantes. Na Extensão, baseado no desenvolvimento de oficinas de informática com estudantes e professores de Ensino Médio, coletaram-se dados a partir de filmagem das sessões, após a sua transcrição, a organização e a análise consideraram a argumentação presente nas narrativas, momento em que a capacidade argumentativa manifestada pelos estudantes contemplou linguagens verbal, não-verbal e escrita. Finalmente, no Trabalho de Conclusão 
de Curso, o estudo concentrou-se basicamente na argumentação de professores de matemática de Ensino Médio.

Neste artigo, apresentam-se reflexões teóricas a respeito da Linguagem e suas formas de Representação, da Produção de argumentação em torno de situações interpretativas de matemática e das Tecnologias Informáticas e Educação Matemática, além de dados da pesquisa acompanhados de análise da argumentação dos sujeitos. O presente texto foi produzido e apresentado em palestra desenvolvida na II Escola de Inverno de Educação Matemática que ocorreu na Universidade Federal de Santa Maria, UFSM, RS, no ano de 2010.

\section{A linguagem e as formas de representação}

A concepção de linguagem assumida na pesquisa ultrapassa a escrita e a fala. O ato de comunicar é considerado um ato de intercâmbio linguístico entre dois interlocutores, ou seja, professor-aluno ou aluno-aluno e a comunicação humana é considerada como forma de interação social entre indivíduos, como descreve Vigotsky. Assim, a linguagem passa a englobar o interpretar, o criar significados, o imaginar, o compreender e o extrapolar.

A linguagem não verbal envolve o gesto que se destaca como expressão do corpo, movimento corporal que, agregado à fala, manifesta ideias, pensamentos, entendimentos. Dois tipos de expressões para os gestos são considerados segundo Scheffer (2002): o gesto como experiência interpretati$v a$, que é a maneira pela qual se pode interpretar os movimentos corporais realizados com o sensor; e o gesto explicativo, que é a recuperação e reelaboração da situação vivenciada. Assim, a linguagem gestual na situação em pesquisa abrange o gesto como experiência interpretativa com gráficos e o gesto explicativo do gráfico construído.

Portanto, a linguagem corporal é um modo de comunicação, uma forma complexa de interação interpessoal, que pode ser realizada de forma verbal ou não-verbal.

Quando se fala de linguagem, vale considerar Maturana (1999), ao destacar que o peculiar do humano não está na manipulação, mas na linguagem e no entrelaçamento com o emocionar. Para o autor, a linguagem é um sistema simbólico de comunicação que se constitui num fluir de coordenações consensuais de ações, ou seja, na concordância de ideias. O autor utiliza o termo "linguajar" enfatizando seu caráter de atividade, de comportamento, sustenta que não há ação humana sem uma emoção e, para ele, essa emoção é o amor que constituiu o domínio em que nossas interações 
com o outro se tornam convivência. Assim, a função da linguagem de acordo com o autor, inclui a expressão de sentimentos, emoções, a transmissão de mensagens cujos significados são influenciados pelo contexto.

Segundo Maturana (1999), a linguagem não se dá no corpo como um conjunto de regras, mas sim no fluir em coordenações consensuais de condutas. E a linguagem como fenômeno ocorre no espaço de relações e pertence ao âmbito das coordenações de ação, como um modo de fluir nelas.

Seguindo a linha de pensamento do autor, o fato de nos encontrarmos na linguagem é que, quando refletimos sobre a linguagem, já estamos nela. Nessas circunstâncias, existem duas atitudes possíveis diante do conhecer: ou aceitamos nossa capacidade de conhecer como uma condição dada, ou nos perguntamos como é que conhecemos. Assim, explicar é sempre propor uma reformulação da experiência a ser explicada de uma forma aceitável para o observador e, no momento em que uma reformulação da experiência é aceita como reformulação, ela se constitui numa explicação.

Portanto, de acordo com Maturana (1999), ao aceitar que nossa capacidade de observar resulta de nossa biologia, e que chamamos de caminho da objetividade, caminho explicativo, nossa corporalidade nos constitui e o corpo não nos limita, mas nos possibilita. Em outras palavras, entendemos que é através de nossa realização como seres vivos que somos seres conscientes que existem na linguagem.

Na matemática, é comum a análise e a busca explicativa para as descobertas, o que caracteriza a originalidade e a especificidade do pensamento matemático. Segundo Duval (2003), a diferença entre a atividade cognitiva requerida pela matemática e aquela requerida em outros domínios do conhecimento não deve ser procurada nos conceitos, mas na importância primordial das representações semióticas, conforme se pode observar no desenvolvimento da matemática e na grande variedade de representações semióticas utilizadas na matemática.

A importância do desenvolvimento das representações semióticas foi, segundo o autor, condição essencial para a evolução do pensamento matemático. A variedade das representações semióticas utilizadas em matemática vai além dos sistemas de numeração, figuras geométricas, escritas algébricas e formais, representações gráficas e a língua natural, estas, são utilizadas para designar os diferentes tipos de representações.

Neste estudo, nos deteremos nas representações discursivas (narrativas, falas e argumentações), não-discursivas (gráficos no plano cartesiano) e na possibilidade de passar de um registro para outro. A compreensão em matemática, 
de acordo com Duval (2003), supõe a coordenação de ao menos dois registros de representaç̃os semióticas: a transformação de uma representação em outra, que geralmente é considerada uma operação simples e local, e o ato da conversão que seria uma das formas mais simples de tratamento.

Passar de uma equação à sua representação gráfica constituiria uma codificação associada a um par ordenado no plano cartesiano. Segundo Duval (2003), essa conversão supõe que se consiga levar em conta as variáveis visuais próprias dos gráficos e de outro lado os valores escalares das equações. Então, (de acordo com) para o autor, é na articulação dos registros que se constitui a condição de acesso à compreensão matemática.

\section{A produção de argumentação em torno de situações interpretativas de matemática}

A produção de argumentos é uma forma de expressar algo que sintetize formas de pensar, aglutine em níveis mais claros a compreensão do todo. Os estudantes revelam, através de palavras e gestos, as suas conclusões sobre determinada experiência, elaborando de modo cada vez mais consciente e conciso suas explicações para tal experiência.

Segundo Koch (1997), quando os indivíduos interagem, procuram permear seus enunciados de uma "força argumentativa" e de interações sociais através de uma língua, dotadas fundamentalmente pela argumentatividade, habilidade que é revelada através de diferentes mecanismos, destacando-se as pressuposições, as marcas de intenção, os operadores argumentativos e os modalizadores.

Quando se interpreta a mensagem que traz a música "Eu só peço a Deus", cantada e interpretada por Mercedes Sosa, intermediada por imagens que retratam a realidade da pobreza material e espiritual do homem, é possível identificar marcas de argumentatividade circundadas por interações sociais que a língua apresenta no movimento do viver e conviver dos homens. O mesmo acontece com a representação e interpretação da Mensagem "Um pai cuida de dez filhos, mas dez filhos não cuidam de um Pai" por Zezé di Camargo ao fazer um comercial para o governo de Minas, que se volta à valorização e atenção para com o idoso. Nesse comercial, o cantor apresenta uma forma pessoal de argumentar e manifestar sentimentos de carinho e cuidado para com o idoso, o que expressa um argumento de muita emoção e sentimento. 
De acordo com Ramos (2004, p.28), a argumentação faz parte da nossa vida, vivemos numa sociedade comunicativa e argumentativa. As expressões argumentativas que foram investigadas e analisadas neste estudo são consideradas enquanto formas da manifestação de Linguagem Matemática e da Capacidade Argumentativa. Desse modo, as diferentes linguagens consideradas como formas de manifestação são a verbal, não-verbal e a escrita.

Nesse sentido, a argumentação é considerada como função da linguagem, composta por expressões da linguagem oral ou gestual, utilizadas cotidianamente, independentemente da intencionalidade do locutor. No caso deste estudo, as manifestações de linguagem consideradas foram utilizadas para interpretar gráficos cartesianos representativos de movimentos corporais.

A partir da análise das argumentações orais ou escritas, chama-se a atenção para questões que estão presentes no diálogo e na produção escrita também. Assim, a argumentação, do ponto de vista da retórica, cede lugar à argumentação sob a perspectiva da semântica argumentativa, com a qual os estudantes e professores se manifestam, fazendo uso de diferentes marcas linguísticas em sua narração, aliadas às marcas corporais e gestuais.

Ao voltar o olhar à Matemática, esta possui uma linguagem própria, apresenta-se constituída de código e gramática própria e, assim, a Linguagem Matemática pode ser expressa através de diferentes registros como qualquer linguagem. Por outro lado, quando veiculada no contexto escolar, nem sempre é esclarecedora, gerando-se aí certa ansiedade quanto ao texto matemático discutido e apresentado nas aulas de matemática.

A linguagem verbal envolve o discurso, que é considerado a própria palavra em movimento. Trata-se de uma prática de linguagem que observa o homem falando, procurando compreender a língua fazendo sentido, enquanto parte do trabalho simbólico, parte do trabalho social geral, constitutivo do homem e da sua história (ORLANDI, 2007: 15).

Nesse sentido, o discurso assume um papel fundamental no trabalho escolar, pois o valor das manifestações dos alunos é fundamental para descrever os significados matemáticos atribuídos em sala de aula. Autores como Heidegger e Ricoeur referem-se ao termo discurso como manifestações escritas ou orais da língua, que pode ser definido de diversas maneiras. Segundo Martin Heidegger (1984), o discurso fundamenta a linguagem, entes e seres se manifestam. Essa posição do autor deixa clara a valorização de formas de manifestação do corpo. Por outro lado, para Ricoeur (1971), o discurso pode ser mostrado para o outro por meio de palavras. Este autor valoriza a palavra, o que põe em evidência a linguagem verbal. 
Assim, ao relacionar a linguagem matemática e o discurso matemático, podemos dizer que a linguagem matemática é expressa pelo discurso matemático. E o discurso matemático é constituído por sinais e símbolos e é mostrado por proposições e significados matemáticos

Isso vem a ser esclarecido por Santos (2009, p. 121), quando diz que a comunicação na aula de matemática pode ser analisada em dois sentidos:

[...] o primeiro diz respeito às formas de interação e discursos utilizados por alunos e professores; o segundo refere-se às representações simbólicas e algumas práticas discursivas de que se faz uso no processo de aprendizagem, para promover a compreensão e a comunicação de significados matemáticos.

Nesse processo, a linguagem ocupa papel central e as diferentes formas de linguagem (oral, escrita, gestual, pictórica e corporal) possibilitam a comunicação. Assim, de acordo com Nacarato et al (2009), a comunicação possibilita ao professor a identificação do progresso dos alunos e de suas dificuldades, deixando os processos de argumentação e construção de conhecimentos indissociáveis, os quais podem ser ampliados em ambientes de comunicação de ideias.

Vale aqui trazer novamente Maturana (1999, p.59), quando diz que a linguagem se constitui quando se incorpora ao viver, como modo de viver, e este fluir, em coordenações de conduta que surgem na convivência como resultado dela, quando ocorrem as coordenações de condutas de forma consensual.

Assim, narrativa, que é considerada o relato do diálogo explicativo, que possui uma sequência na descrição de eventos, de acordo com Scheffer (2002), passa a ser uma maneira de o ser humano expressar e comunicar uma ideia, fenômeno ou situação, descrever um acontecimento com sequência temporal, utilizando símbolos matemáticos que representam a interpretação e o significado atribuído. Além de valorizar os conhecimentos do estudante, as experiências vivenciadas viabilizam a criação de ambiente de experimentação e criação.

Para Alro e Skovsmose (2006), as relações interpessoais têm papel importante para o diálogo. Pois, um diálogo não é uma conversação como outra qualquer, mas sim um elemento fundamental para a liberdade de aprender o que é definido como o encontro entre pessoas, a fim de "dar nome ao mundo", o que significa conversar sobre os acontecimentos e a possibilidade de alterar o seu curso.

Em confirmação e, ainda, de acordo com o mesmo autor, o diálogo é visto como algo existencial que não pode existir sem amor e respeito pelo mundo 
e pelas pessoas, ele não pode existir em relações de dominação. Portanto, uma vez que o diálogo é motivado por uma expectativa de mudança, ele não pode existir sem o engajamento das partes com respeito ao crescimento crítico.

Para Maturana (1999, p.55), o que explicamos é sempre uma experiência. Por isso, quem descreve o que vai explicar, descreve o que tem de fazer para ter a experiência que se quer explicar. A linguagem, de acordo com o mesmo autor (1999, p.27), não se dá no corpo como um conjunto de regras, mas sim no fluir em coordenações consensuais de condutas. A linguagem, como fenômeno, ocorre no espaço de relações e pertence ao âmbito das coordenações de ação, como um modo de fluir nelas.

Seguindo a linha de pensamento do autor, o fato de nos encontrarmos na linguagem é também algo que simplesmente ocorre conosco. Quando refletimos sobre a linguagem, já estamos nela. Nessas circunstâncias, existem duas atitudes possíveis diante do conhecer: ou aceitamos nossa capacidade de conhecer como uma condição dada, ou nos perguntamos como é que conhecemos.

Consequentemente, ao seguir o caminho explicativo, nossa corporalidade nos constitui e o corpo não nos limita, mas nos possibilita. Em outras palavras, entendemos que é através de nossa realização como seres vivos que somos seres conscientes de que existem na linguagem.

\section{Tecnologias informáticas e Educação Matemática}

A Informática e outras mídias assumem espaço na educação atual, enriquecem o trabalho exploratório desenvolvido pelo professor no contexto escolar, principalmente dos níveis Fundamental e Médio.

O professor é desafiado a transformar sua prática, transformação essa que não se realiza de forma evidente, exige envolvimento dos sujeitos professor e aluno. Os ambientes de aprendizagem constituem um fator de motivação dos estudantes, sendo uma forma de considerar a utilização de recursos tecnológicos diferenciados e computadores.

Uma discussão com esse foco em ambientes virtuais de aprendiaegem não pode ocorrer sem a participação de professores e estudantes, porque, no contexto atual, o trabalho com tecnologias informáticas está diretamente relacionado com a realidade escolar. Isso é confirmado por Penteado 
(2004) quando afirma que não é possível pensar na inserção de TIC na escola sem formação e envolvimento dos professores, o que ainda ocorre no Brasil, a partir de ações fragmentadas.

A utilização planejada dos softwares possibilita uma opção didática que abrange um ambiente investigativo de ensino e de aprendizagem, promovendo a construção de conhecimentos e tendo compromisso com a formação criativa dos indivíduos. Essa formação é tida como condição ao desenvolvimento da iniciativa, tomada de decisões e consciência crítica em relação à realidade.

Assim, tais ambientes são considerados válidos para o ensino e aprendizagem da Matemática nos diferentes níveis de ensino, por possuírem interface propícia à investigação, apresentando resolução gráfica, linguagem coerente e praticidade. Além disso, esses ambientes disponibilizam comandos de fácil manejo e entendimento e proporcionam itens de ajuda que facilitam a sua exploração.

Quando voltamos o olhar para questões didáticas de sala de aula trazidas pelo uso da informática na educação, destaca-se a importância da criatividade, que, para Pais (2002), é vista como o resultado de uma persistente experiência de trabalho, habilidades fundamentais para o sucesso da aprendizagem. Este autor considera que um dos primeiros desafios surgidos com a utilização do computador na escola é o de desenvolver competências e habilidades suficientes à seleção de informações pelo próprio sujeito da aprendizagem.

Desse modo, o uso das tecnologias, visando a desenvolver o processo de descoberta matemática e incentivando a compreensão matemática, possibilita a realização de um trabalho mais abrangente no ensino.

No ambiente interativo, o software educativo pode ser definido como um conjunto de recursos informatizados cujo objetivo é facilitar a aprendizagem, Scheffer (2006). Esses ambientes permitem ao estudante, mediado pelo professor, produzir conhecimentos, desenvolver habilidades como resolução de problemas, leitura, imaginação, criatividade e exercício dos conteúdos que já conhece.

A utilização de softwares gratuitos na educação, a partir do projeto que vem sendo desenvolvido com acadêmicos e professores, tem sido considerada alternativa para o ensino, por serem acessíveis, sem custo e estratégicos à condução bem sucedida de conteúdos matemáticos na sala de aula.

Nessa perspectiva, a incorporação de novos recursos tecnológicos na sala de aula de Matemática resulta na criação de ambientes de aprendizagem que levam o aluno ao desenvolvimento de novos conceitos e à consolidação da aprendizagem. 


\section{Discussão e análise:}

\section{argumentação Matemática}

Nesta parte do artigo, considera-se o discurso como algo que se refere às manifestações escritas ou orais da língua, no caso concreto, àquelas que acontecem no contexto escolar, mais especificamente em atividades de matemática realizadas em interação com tecnologias.

Apresenta-se a seguir dois exemplos que fizeram parte da prática realizada com os sujeitos da pesquisa para ilustrar a exploração e valorização da argumentação matemática na análise de gráficos representativos de movimentos corporais, realizados com o Sensor de Movimento CBR', adaptado à Calculadora Gráfica TI 83.

No gráfico gerado aleatoriamente pelo Programa Ranger Applications da Calculadora Gráfica (Fig.1), pode-se observar, na linha contínua, a representação de uma função de várias sentenças. A partir da sua interpretação, é possível reconstituir um movimento corporal a ser realizado com o sensor CBR. A linha pontilhada representada logo abaixo, constitui-se na reprodução do movimento corporal, realizado com o sensor considerando a interpretação das funções representativas no gráfico.

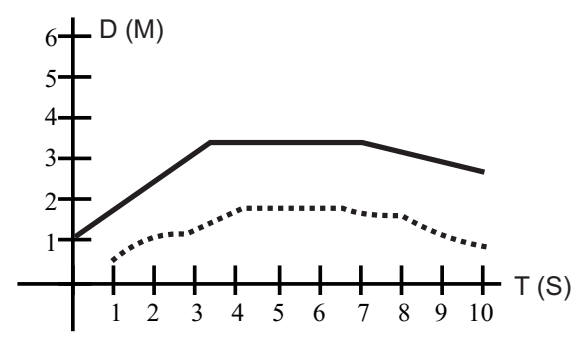

Figura 1. Gráfico do Programa Ranger Applications².

O movimento está descrito a partir de três intervalos:

(1) $0 \leq x \leq 3,5$; (2) $3,5 \leq x \leq 7$ e (3) $7 \leq x \leq 10$. 
Assim, pode-se aproximar a representação gráfica do movimento com três diferentes funções: (1) afim crescente, (2) função constante e (3) função afim decrescente.

A interpretação do movimento a ser gerado a partir desse gráfico é inicialmente de afastamento, depois de ausência de movimento, ou seja, repouso de aproximadamente 4 segundos, e, por fim, de um movimento de aproximação em relação ao plano de referência.

Para cada intervalo, aproxima-se uma lei matemática que descreve diferentes funções para o mesmo gráfico. A análise matemática evidencia que os gráficos (Figs. 1 e 2), na representação, são compostos de três intervalos de variação: (1); (2) e (3). Sendo que, para esses intervalos, aproximam-se leis matemáticas que descrevem as funções:

(1) $0 \leq x \leq 3,5 ; y=0,5461 x+1,1402$

(2) $3 \leq x \leq 7 ; y=3$

(3) $7 \leq x \leq 10 ; y=-0,2222 x+4,5556$

Outra possibilidade explorada nessa atividade foi a representação gráfica a partir das funções encontradas no software Winplot. Conforme a figura 2, essa opção oportuniza ao estudante e professor testar as funções e obter uma construção gráfica que possibilita checagem das funções, discussão de resultados e interpretação das diferentes funções.

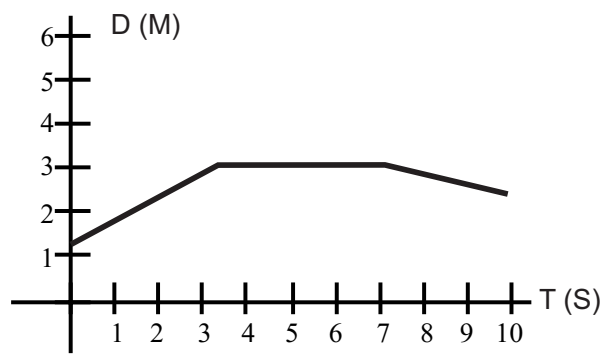

Figura 2. Gráfico do Software Winplot.

${ }^{2}$ Esta representação (Fig.1) não apresenta boa qualidade porque foi obtida a partir da tela da Calculadora TI 83, motivo pelo qual o seu desenvolvimento em tela gráfica não é tão nítido quanto o da figura 2, que tem sua origem no Software Winplot. 
No gráfico da figura 3, temos outra representação de movimento gerada aleatoriamente pelo Programa Ranger Applications da Calculadora Gráfica e pode-se observar a representação de outra função de várias sentenças

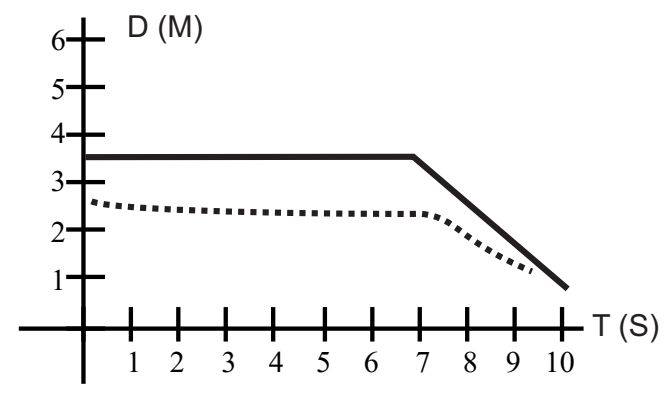

Figura 3. Gráfico do Programa Ranger Applications.

A interpretação do movimento a ser gerado a partir deste gráfico é inicialmente de ausência de movimento, ou seja, repouso, e depois de aproximação do plano de referência. Para cada intervalo (1) e (2), aproximam-se as leis matemáticas que descrevem as seguintes funções para o mesmo gráfico.

(1) $0 \leq x \leq 7 ; y=3$

(2) $7 \leq x \leq 10 ; y=-0,25 x+2,75$

Pode-se aproximar a representação gráfica do movimento com duas diferentes funções: (1) função constante, e (2) função afim decrescente, que representam um período de repouso, ou seja, um período em que a distância entre o sensor e o plano de referência ficou mantida de aproximadamente 7 segundos, e, por fim, de um movimento de aproximação em relação ao plano de referência no decorrer dos próximos 3 segundos.

Aqui temos uma forma de representação não-discursiva, de acordo com Duval (2003), que suscita uma interpretação e representação discursiva, o que tem por consequência a transformação de uma representação em outra. 


\section{Análise da argumentação}

\section{As manifestações não-verbais}

Para o intervalo do gráfico matemático representado pela Função Crescente, o movimento corporal representativo é de afastamento do Sensor, em relação ao plano de referência e o gesto destacado para o movimento e seu respectivo gráfico, ele foi um gesto ascendente com o dedo indicador, o que representa um movimento de afastamento do plano de referência

Para o intervalo do gráfico matemático representado pela Função Constante, o movimento corporal representativo é de repouso, ou seja, ausência de movimento, e o gesto destacado para ele foi um gesto que indica para o horizonte; depois indica a linha no intervalo constante do gráfico ascendente com o dedo indicador, o que representa ausência de movimento.

Para o intervalo do gráfico matemático representado pela Função Decrescente, o movimento corporal representativo é de aproximação do Sensor, em relação ao plano de referência e o gesto destacado para ele foi um gesto descendente com o dedo indicador, o que representa o movimento de aproximação do plano de referência, apontando com o dedo indicador sobre o traçado decrescente do gráfico.

\section{As manifestações verbais}

Para a Função Crescente que representa o movimento de afastamento do Sensor, em relação ao plano de referência, as manifestações verbais são: "[...]quando me afasto é subindo [...]"; "[...]quando se afasta, sobe".

Para a Função Constante que representa um repouso do Sensor, ou seja, ausência de movimentos, as manifestações verbais são: "A distância (se mantém inalterada), porque não movimenta"; "[...] e depois fica parado".

Para a Função Decrescente que representa um movimento de aproximação do Sensor, em relação ao plano de referência, as manifestações verbais são: "Comecei a me $\underline{e}^{3}$ aproximar da parede [...]"; "Aí eu me aproximei"; "A curva que desce é quando me aproximo [...]”; "Quando se aproxima, a parábola desce”. 


\section{ciênciannatura UFSM, 34(1)}

Expressões argumentativas manifestadas

verbalmente pelos estudantes

Quando: relação de tempo simultâneo.

Eu /me: comprometimento, efeito de sentido argumentativo.

E: adiciona argumentos em favor de um outro, já enunciado.

Depois: sentido de sequencialidade; relação de tempo posterior; recurso linguístico.

Se: relação de condicionalidade (se P então Q) - conexão de duas orações; argumento sobre a velocidade.

De novo: reforça um argumento já enunciado, retomando algo já feito ou pronunciado; recurso linguístico.

Mais: refere-se a algo pressuposto; modalizador de intensidade.

Mais ou menos: operador argumentativo de dúvida, incerteza ou imprecisão de dados.

Essas expressões constituem-se na explicação que Maturana destaca como reformulação da experiência. Explicar é sempre propor uma reformulação da experiência a ser explicada de uma forma aceitável para o observador. No momento em que uma reformulação da experiência é aceita como reformulação da experiência, ela se constitui numa explicação.

\section{Conclusão}

As expressões argumentativas acima destacam uma discussão clara quanto às diferentes formas de manifestação de linguagem oral, corporal e gestual, expressas na argumentação, o que se constitui em possibilidades de exploração matemática utilizando tecnologias. Isso vem a confirmar as definições quanto ao discurso consideradas no texto, por Heidegger (1984), que coloca o discurso como algo que fundamenta a linguagem e os entes e seres se manifestam e, por Ricoeur (1971), que destaca o discurso a ser mostrado para o outro, por meio de palavras, evidenciando assim a linguagem verbal.

Outro aspecto que se pode observar é que, em toda argumentação ocorre o uso de uma linguagem auxiliar. Esta pode ser a linguagem do seu próprio corpo, os gestos das mãos, dos braços, como complemento das suas usuais palavras para atribuir significado matemático à fala, à narração, e demais aspectos a serem considerados pelo professor nas aulas de matemática.

Assim, o uso de diferentes marcas linguísticas aliadas a marcas corporais e gestuais (gestos interpretativos e explicativos) possibilita manifestar 
tanto o significado matemático atribuído às situações de movimento vivenciadas, quanto a argumentação por meio de operações argumentativas intrínsecas às suas falas.

A partir das investigações, tanto com estudantes como com professores de matemática, é possível dizer que o discurso veiculado no meio escolar com tecnologias torna possível a valorização das diferentes formas de representações, e que a argumentação faz parte do cotidiano escolar, não apenas no processo de ensino e de aprendizagem da matemática, como também na formação cidadã de cada sujeito envolvido no processo.

Desse modo, as respostas, como um todo, evidenciam que a maioria dos sujeitos se manifesta de maneira amistosa, demonstrando uma postura de mudança que inclui a cultura da argumentação, denotando a valorização de um trabalho diferenciado e voltado à prática argumentativa.

\section{Referências}

ALRO, H.; SKOvSMOSE, O. Diálogo e Aprendizagem em Educação Matemática. Belo Horizonte: Autêntica Editora, 2006.

DUVAL, R. Registros de representações semióticas e funcionamento cognitivo da compreensão em matemática. In: MACHADO, S. D. A. (Org.) Aprendizagem em Matemática: Registros de representação semiótica. Campinas, SP. Editora Papirus, 2003. p. 11-35.

HeIDEGGER, M. El ser y el tiempo. Trad: José Gaos. México: Fundo de cultura econômica, 1984 .

KOCH, I. V.; TRAVAGLiA, L. C. A Coerência Textual. 8 ed. São Paulo: Contexto, 1997. maturana, h. Emoções e Linguagem na Educação e na Política. Belo Horizonte: Ed. UFMG, 1999.

NACARATO, A. M.; MENGALI, B. L; PASSOS, C.L.B. A matemática nos anos iniciais do Ensino Fundamental: Tecendo fios do ensinar e do aprender. Belo Horizonte: Autêntica Editora, 2009. Cap 3, p. 51-79.

ORLANDI, E. P. Análise de Discurso: princípios e procedimentos. 7 ed. Campinas, S P: Pontes, 2007.

PAIS, L. C. Educação Escolar e as Tecnologias da Informática. Belo Horizonte, MG: Autêntica, 2002. 
PENTEADO, M. G. Redes de trabalho: expansão das possibilidades da informática na educação matemática da escola básica. In BICUDO, M. A. V.; BORBA, M.C. Educação matemática: pesquisa em movimento. São Paulo: Cortez, 2004, p. 283-295.

RAMOS, M. G. Educar pela pesquisa é educar para argumentação. In: MORAES. R.; LIMA, V. M. R. (Orgs.) Pesquisa em sala de aula - Tendências para a Educação em novos tempos - 2 ed. Porto Alegre: EDIPUCRS, 2004, p.25-51.

RICOEUR, P. Teoria da interpretação. Trad. por Artur Morão, Lisboa: Edições 70, 1971. SANTOS, V. M. Linguagens e comunicação na aula de matemática. In NACARATO, A. M.; LOPES, C. E. (Orgs). Escritas e Leituras na Educação Matemática, Belo Horizonte: Autentica, 2005, p. 117-125.

SCHEFfeR, N. F. Corpo-Tecnologias-Matemática: Uma Interação Possível no Ensino Fundamental. Erechim: Edifapes, 2002.

SCHEFFER, N. F.; PEDRoso, C. A. Uma Discussão a Respeito de Software Livre de Matemática para o Ensino Fundamental e Médio e a Formação de Professores. Erechim, RS. PIIC-URI, 2006.

Submetido em: 24/03/2011

Aceito em: 03/11/2011 